\title{
Runner Plant Cold Storage Reduces Verticillium dahliae Infection of Nursery Origin in Strawberry
}

\author{
Douglas V. Shaw ${ }^{1}$, Thomas R. Gordon ${ }^{2}$, and Kirk D. Larson ${ }^{1}$ \\ University of California, Davis, CA 95616 \\ Additional index words. chloropicrin, methyl bromide, Fragaria $\times$ ananassa
}

\begin{abstract}
Strawberry runner plants from the cultivar 'Selva' (Fragaria $\times$ ananassa Duch.) were produced using three nursery treatments in each of three years: propagation in soil fumigated with a mixture of 2 methyl bromide: 1 chloropicrin (w/w) at $392 \mathrm{~kg} \cdot \mathrm{ha}^{-1}$, propagation in fumigated soil but using planting stock inoculated prior to nursery establishment with a conidial suspension of Verticillium dahliae $\left(10^{6}\right.$ coni$\mathrm{dia} / \mathrm{mL}$ ), and propagation in nonfumigated soil naturally infested with $\boldsymbol{V}$. dahliae. Runner plants were harvested and stored at $1^{\circ} \mathrm{C}$ for 6,18 , or 34 days prior to establishment in fruit production trials. No significant differences were found between runner plants grown in naturally infested soil and runner plants obtained from artificially inoculated mother plants for $V$. dahliae infection rates detected by petiole isolation immediately prior to transplanting, the percentage of plants visibly stunted due to disease during the following production season, and seasonal yield compared with corresponding noninfected controls. Cold storage of runner plants for 18 or 34 days, produced using either natural or artificial inoculation systems, reduced the initial percentage of infected plants by $42 \%$ to $61 \%$ and the percentage of stunted plants during the following fruit production season by $43 \%$ to $57 \%$, compared with plants from corresponding nursery treatments given only 6 days post-nursery cold storage. Yields for inoculated plants with 6 days cold storage were $16 \%$ to $20 \%$ less than those for uninoculated controls, whereas yields for inoculated plants with 18 or 34 days of storage were $3 \%$ to $9 \%$ less than the respective controls. Most of the cold storage effects on initial infection rate, stunting, and yield were realized at the 18 days of storage treatment. A reduction in the fraction of $V$. dahliae infected plants due to cold storage, suggests either a direct effect of cold storage on the disease organism or stimulation of secondary resistance mechanisms in the plant. Chemical name used: trichloronitromethane (chloropicrin).
\end{abstract}

During the past century, Verticillium dahliae Kleb. was considered one of the most important pathogens of strawberry (Fragaria $\times$ ananassa Duch.) in California (Paulus, 1990; Thomas, 1932). The development of successful methods of preplant soil fumigation with methyl bromide and chloropicrin (Wilhelm and Koch, 1956) together with widespread adoption of annual planting systems (Voth and Bringhurst, 1990) virtually eliminated severe soil infestations of $V$. dahliae in California fruit production fields (Wilhelm and Paulus, 1980; Wilhelm et al., 1974). Although the disease is not widespread at present, recent reports of significant $V$. dahliae infection suggest that the disease currently enters the strawberry cultivation system primarily through the final stage of propagation (Gordon et al., 2001), in facilities usually referred to as high elevation nurseries (Larson and Shaw, 2000). Soil fumigation is standard practice for California strawberry nurseries (Larson and Shaw, 1995). However, strawberry nursery sites are frequently planted in rotation with crops that

Received for publication 29 May 2001. Accepted for Publication 11 Nov. 2001. We wish to thank Lassen Canyon Nursery for their generous assistance in conducting the nursery phases of this research.

${ }^{1}$ Pomology Dept.

${ }^{2}$ Plant Pathology Dept. serve as favorable $V$. dahliae hosts, and are occasionally inadequately fumigated due to adverse climate conditions during treatment. Once established, $V$. dahliae has proven recalcitrant in both strawberry nurseries and fruit production fields, as soils heavily infested with this pathogen may require repeated fumigation treatments to reach the very low levels of infestation required for avoidance of disease symptoms (Wilhelm and Koch, 1956). For nurseries, the disease is further problematic, because infection is transmitted from the mother plant to its daughter runner plants through stolons (Gordon et al., 2001), thus relatively low levels of field infection can result in rather high frequencies of infected runner plants at nursery harvest. Because susceptible rotation crops together with difficult fumigation conditions can result in $V$. dahliae infection and subsequent transfer of infected runner plants to fruiting fields, and because most of the commonly used cultivars available to growers in California are at least moderately susceptible to this disease (Shaw et al., 1996), the need for cultural methods of $V$. dahliae management is critical.

For most strawberry cultivars used in annual production systems, the physiological effects conditioned by nursery environments and post-nursery treatments applied to strawberry runner plants prior to establishment in the fruit production field are at least as important to their performance as plant diseases (Larson and Shaw, 2000). Although these environmental and cultural treatments can affect a range of physiological responses, their key feature is the chilling invoked by a combination of factors including nursery location, harvest date, and post-harvest cold storage (Larson, 1994; Voth and Bringhurst, 1970, 1990). Many of the physiological effects of runner plant chilling for strawberry growth and performance are well documented, most of which enhance the vigor of the runner plant and affect its eventual resource partitioning (Albregts and Howard, 1985; Durner et al., 1984; 1987; Voth and Bringhurst, 1970; 1990). The downstream consequences of runner plant chilling in strawberry may affect a number of pest resistance responses as well, for example chilling has been shown to decrease susceptibility to spider mites (Walsh et al., 1997).

The studies reported here were initiated after anecdotal observations on nursery stock infected with $V$. dahliae through accidental soil contamination indicated reduced stunting in the fruit production field when runner plants were treated with several days of postnursery cold storage prior to planting (Shaw and Gordon, personal observtion). We evaluated $V$. dahliae infection rates and percentage of stunting for strawberry runner plants from a moderately susceptible cultivar, using two inoculation methods and a range of postnursery cold storage treatments.

\section{Materials and Methods}

Nursery experiments were established near Macdoel, Calif. (lat. $41^{\circ} 8^{\prime} \mathrm{N}$, elev. $\approx 1300 \mathrm{~m}$ ) in late April of 1997, 1998, and 1999. These nursery sites had been used most recently for production of various agronomic crops, including wheat (Triticum aestivum L.), annual rye (Secale cereale L.), sugar beets (Beta vulgaris L.), alfalfa (Medicago sativa L.), and potatoes (Solanum tuberosum L.), the latter being an especially good host for Verticillium wilt (Davis et al., 1996). None of the three sites used for our studies had been used for strawberry nurseries prior to these trials.

In each of the three years, certified runner plants of the cultivar 'Selva' were planted in soils fumigated with 2 methyl bromide: 1 chloropicrin (w/w) at $392 \mathrm{~kg} \cdot \mathrm{ha}^{-1}$ during the spring of the planting year or in nonfumigated soils naturally infested with $V$. dahliae. Soil samples obtained from nonfumigated plots were assayed for propagules of $V$. dahliae as described by Gordon et al. (2001). These assessments yielded estimates of $18.8( \pm 10.9)$, $20.3( \pm 3.4)$, and $26.0( \pm 6.0)$ microsclerotia/g of soil for trials established in 1997, 1998, and 1999, respectively, thus assuring substantial disease pressure at each of the three sites. A third nursery treatment was established by treating certified stock with a conidial suspension of $V$. dahliae $\left(10^{6}\right.$ conidia/ $\mathrm{mL}$ ), then planting them in fumigated soil (Shaw et al., 1997). Statistical comparisons of nursery variables were not planned as part 
of this experiment, but two or three replicates of each treatment with 10-25 mother plants per replicate were established each year to sample any variation due to spatial heterogeneity for $V$. dahliae and other site factors.

Runner plants were harvested from the Macdoel nursery plots on 14 or 15 Oct. in each of the three trial years, combined over replications, trimmed, and stored at $1^{\circ} \mathrm{C}$ until planting in fruiting trials. The consequences of supplemental cold storage were evaluated using plants stored for 6,18 , and $34 \mathrm{~d}$ prior to establishment for fruiting trials established in 1997 and 1998, and for 6 and $18 \mathrm{~d}$ for the 1999 trial.

Petiole segments $\approx 2 \mathrm{~cm}$ in length were sampled within $24 \mathrm{~h}$ prior to fruiting trial establishment and evaluated for infection by $V$. dahliae as described by Gordon et al (2001); SEs for the percentage of plants with infected petioles were obtained using the binomial sampling formula (Steele and Torrie, $1980)$ and statistical significance was determined using Chi-square $\left(\chi^{2}\right)$ tests for goodness of fit and heterogeneity.

Fruit production trials were established after cold storage treatments near Watsonville, Calif. (lat. $36^{\circ} 54^{\prime} \mathrm{N}$, long. $121^{\circ} 48^{\prime} \mathrm{W}$ ) and treated according to recommendations for annual commercial winter planting systems (Welch, 1989). Experimental plots were established on two-row raised beds with 1.32-m centers and 0.36 -m in-row plant spacing. Three replicates, each containing a single plot of 20 runner plants (occasionally fewer) per nursery/cold storage treatment, were established for the 1997 and 1998 trials, whereas four replicates were used for the 1999 trial. Fruit yield was recorded weekly, for 24 to 27 consecutive weeks during the spring and summer following planting in each trial year, with harvest initiated the second or third week of April. The percentage of plants severely stunted and showing disease symptoms was recorded for each plot on 8 July 1998, 16 July 1999, and 1 Aug. 2000 for the three trials, respectively. Analyses of variance (ANOVA) for seasonal yield and the percentage of stunted plants were performed with years, nursery fumigation treatment, and length of cold storage as fixed effects; replications were nested in years and were used as the error term for testing the main effects of years. Angular transformations were performed where variances were heterogeneous. However, these transformations had little effect on statistical comparisons for percentage of stunting, so results based on untransformed data are presented here. All ANOVAs were conducted using SAS procedure GLM (SAS Inst., 1988). Analyses of simple effects (Steele and Torrie, 1980) and ANOVAs conducted for individual years were used to clarify significant interaction effects from the combined ANOVA where needed.

\section{Results and Discussion}

The percentage of 'Selva' runner plants with petioles positive for $V$. dahliae immediately prior to transplanting in the fruit production field was affected by both nursery and cold storage treatments (Table 1). Only one of the 155 petioles sampled from runners propagated in fumigated soil in three years proved positive for $V$. dahliae, verifying that soil fumigation had been very effective in these trials. The percentage of runner plants from naturally infested soil with positive petiole isolations $(16.7 \% \pm 0.022)$ did not differ significantly $\left(\chi_{1}^{2}=0.79, P>0.25\right)$ from the percentage of infected in runner plants obtained from artificially inoculated mother plants $(14.8 \% \pm 0.019)$. These inoculation methods appear very similar in effecting $V$. dahliae infection, consistent with prior conclusions that most runner plant infection proceeds by transmission from the mother plant through the stolon (Gordon et al., 2001).

Cold storage of runner plants from either artificial or natural $V$. dahliae nursery inoculation treatment for 18 or $34 \mathrm{~d}$ prior to transplanting in fruit production fields reduced the percentage of detectably infected plants at establishment by $42 \%$ to $61 \%$ compared with plants stored for $6 \mathrm{~d}$ (Table 1). Tests of heterogeneity indicated that initial infection percentages were consistent for artificial and natural inoculation methods $\left(\chi_{2}^{2}=\right.$ $0.82, P>0.75)$. Furthermore, the initial percentage of plants infected after $34 \mathrm{~d}$ storage $(9.2 \% \pm 0.025)$ was smaller than that for $18 \mathrm{~d}$ storage $(12.4 \% \pm 0.020)$, but these treatment means did not differ significantly $\left(\chi^{2}{ }_{1}=0.99\right.$, $P>0.5)$. Thus most of the reduction in initial infection rate was realized with the shorter storage duration. When samples were pooled from both inoculation treatments, petiole assessments prior to transplant detected $21.4 \%$ $( \pm 0.025)$ infection for runner plants with $6 \mathrm{~d}$ post nursery harvest storage, whereas runner plants stored for $18 \mathrm{~d}$ or longer had $11.7 \%$ $( \pm 0.016)$ infection; this difference was highly significant $\left(\chi^{2}{ }_{1}=13.2, P<0.01\right)$.

The percentage of runner plants with visible stunting and disease symptoms during the summer following fruit production trial establishment followed trends similar to those detected in the initial petiole assessments (Table 2). Virtually no stunting was observed for noninoculated plants from fumigated nursery plots $(0 \%$ to $1.5 \%)$, whereas all of the inoculated treatments showed substantial stunting ( $12.0 \%$ to $30.1 \%)$. The percentage of stunting for runner plants treated with either 18 or $34 \mathrm{~d}$ supplemental storage was $43 \%$ to $57 \%$ less than for plants from the corresponding nursery treatments given only $6 \mathrm{~d}$ post-nursery cold storage. ANOVA results (Table 3 ) verified that both nursery and cold storage treatment effects were highly significant $(P<0.01)$ for the percentage of stunting. Interactions between nursery and cold storage treatment were also significant $(P<0.05)$, but analysis of simple effects indicated that these interactions were due to the absence of stunting for runner plants originating from the noninoculated and fumigated nursery treatments. Cold storage treatments reduced stunting significantly for both natural $(\mathrm{F}=13.4,2$ and $69 \mathrm{df}, P<0.01)$ and artificial $(\mathrm{F}=3.86,2$ and $69 \mathrm{df}, P<0.05)$ inoculation treatments.

With samples pooled for inoculation treatments, the percentage of plants identified as diseased in field trials $(19.4 \% \pm 1.67)$ was slightly larger than that detected by pretransplant petiole isolation $(15.5 \% \pm 1.4)$. Subsequent petiole isolations from plants showing visible midsummer stunting symptoms detected $V$. dahliae in $82.6 \%( \pm 2.9 \%)$ of the runner plants tested, suggesting good correspondence but incomplete precision of the isolation procedure.

Table 1. Percentage of 'Selva' strawberry plants with positive petiole isolation for Verticillium dahliae immediately prior to planting from three nursery fumigation treatments and three post-nursery cold storage treatments over 3 years.

\begin{tabular}{lccc}
\hline & \multicolumn{3}{c}{ Supplemental cold storage at $1^{\circ} \mathrm{C}(\mathrm{d})$} \\
\cline { 2 - 4 } Nursery soil treatment & 6 & 18 & 34 \\
\hline Methyl bromide / chloropicrin & 0 & 0 & 1.2 \\
& $(0)$ & $(0)$ & $(1.3)$ \\
Methyl bromide / chloropicrin + inoculation & 19.7 & 11.4 & 10.7 \\
& $(3.4)$ & $(2.6)$ & $(3.6)$ \\
Nonfumigated control & 23.3 & 13.5 & 9.1 \\
& $(3.7)$ & $(3.0)$ & $(3.9)$ \\
\hline
\end{tabular}

${ }_{\mathrm{z}}$ Standard errors from binomial sampling formula in parentheses.

Table 2. Percentage of 'Selva' strawberry plants severely stunted due to Verticillium dahliae 8 July to $1 \mathrm{Aug}$. of the year following planting, and seasonal fruit yield for three nursery fumigation treatments and three post-nursery cold storage treatments averaged over 3 years.

\begin{tabular}{|c|c|c|c|c|c|c|}
\hline \multirow[b]{3}{*}{ Nursery soil treatment } & \multicolumn{6}{|c|}{ Supplemental cold storage at $1^{\circ} \mathrm{C}(\mathrm{d})$} \\
\hline & \multicolumn{2}{|c|}{6} & \multicolumn{2}{|c|}{18} & \multicolumn{2}{|c|}{34} \\
\hline & $\begin{array}{l}\text { Stunted } \\
(\%)\end{array}$ & $\begin{array}{c}\text { Yield } \\
\text { (g/plant) }\end{array}$ & $\begin{array}{l}\text { Stunted } \\
(\%)\end{array}$ & $\begin{array}{c}\text { Yield } \\
\text { (g/plant) }\end{array}$ & $\begin{array}{l}\text { Stunted } \\
(\%)\end{array}$ & $\begin{array}{c}\text { Yield } \\
\text { (g/plant) }\end{array}$ \\
\hline \multirow[t]{2}{*}{ Methyl bromide / chloropicrin } & 1.5 & 944 & 0 & 1132 & 0.8 & 1479 \\
\hline & $(1.0)^{\mathrm{z}}$ & $(60)$ & $(0)$ & $(54)$ & $(0.4)$ & (63) \\
\hline \multirow{3}{*}{$\begin{array}{l}\text { Methyl bromide / chloropicrin } \\
+ \text { inoculation }\end{array}$} & & & & & & \\
\hline & 30.1 & 748 & 12.0 & 1103 & 12.8 & 1357 \\
\hline & $(4.7)$ & $(46)$ & $(2.7)$ & $(84)$ & $(4.4)$ & $(108)$ \\
\hline \multirow[t]{2}{*}{ Nonfumigated control } & 25.9 & 794 & 18.4 & 1032 & 12.9 & 1358 \\
\hline & $(2.8)$ & $(58)$ & $(2.4)$ & $(61)$ & $(3.3)$ & $(92)$ \\
\hline
\end{tabular}

${ }^{\mathrm{z}}$ Standard errors in parentheses. 
Table 3. Analysis of variance results for the percent of 'Selva' plants severely stunted due to Verticillium dahliae 8 July to 1 Aug. of the year following planting, and seasonal fruit yield for three nursery fumigation treatments and three post nursery cold storage treatments over 3 years.

\begin{tabular}{lrcc}
\hline \hline & & \multicolumn{2}{c}{ Mean squares } \\
\cline { 3 - 4 } Source & df & Stunted (\%) & Yield $^{2}$ \\
\hline Year (Y) & 2 & 25.7 & $227.0^{* *}$ \\
Replication / (Y) & 7 & 83.1 & $100.9^{* *}$ \\
Nursery treatment (N) & 2 & $2757.7^{* * *}$ & $123.5^{* *}$ \\
Cold storage (S) & 2 & $760.9^{* * *}$ & $1383.2^{* *}$ \\
$\mathrm{Y} \times \mathrm{N}$ & 4 & 31.1 & 48.7 \\
$\mathrm{Y} \times \mathrm{S}$ & 3 & 42.2 & $83.3^{*}$ \\
$\mathrm{~N} \times \mathrm{S}$ & 4 & $230.5^{*}$ & 23.1 \\
$\mathrm{Y} \times \mathrm{N} \times \mathrm{S}$ & 6 & 60.0 & $50.9^{*}$ \\
Error & 47 & 79.6 & 21.2 \\
\hline
\end{tabular}

${ }^{2}$ Mean squares for yield in thousands.

${ }^{*}, *$ Significant at the $P<0.05$ or 0.01 levels, respectively.

Table 4. Analysis of variance results for seasonal fruit yield by year for three nursery fumigation treatments and three post-nursery cold storage treatments.

\begin{tabular}{|c|c|c|c|c|c|c|}
\hline \multirow[b]{2}{*}{ Source } & \multicolumn{2}{|c|}{1998 Yield $^{2}$} & \multicolumn{2}{|c|}{1999 Yield $^{\mathrm{z}}$} & \multicolumn{2}{|c|}{2000 Yield $^{\mathrm{z}}$} \\
\hline & df & Mean squares & $\mathrm{df}$ & Mean squares & df & Mean squares \\
\hline Replication & 2 & $289.7^{* *}$ & 2 & 38.4 & 3 & 16.8 \\
\hline Nursery treatment $(\mathrm{N})$ & 2 & $135.2^{*}$ & 2 & 17.2 & 2 & $69.3^{* *}$ \\
\hline Cold storage $(\mathrm{S})$ & 2 & $629.4^{* *}$ & 2 & $786.2^{* *}$ & 1 & $68.2^{* *}$ \\
\hline $\mathrm{N} \times \mathrm{S}$ & 4 & $74.3^{*}$ & 4 & 19.3 & 2 & 3.7 \\
\hline Error & 16 & 23.2 & 16 & 33.5 & 15 & 5.7 \\
\hline
\end{tabular}

${ }^{\mathrm{z}}$ Mean squares for yield in thousands.

${ }^{*,}$,** Significant at the $P<0.05$ or 0.01 levels, respectively.

Yields for plants from both artificial and natural inoculation nursery treatments were smaller than for their corresponding noninoculated and fumigated controls regardless of chilling treatment (Table 2). However, cold storage for 18 or $34 \mathrm{~d}$ reduced the differences in yield between inoculated and noninoculated treatments, consistent with the patterns observed for the percentage of initial infection and percentage of plant stunting. With $6 \mathrm{~d}$ post-nursery cold storage, yields for artificially and naturally inoculated treatments were $20 \%$ and $16 \%$ less than those for the uninfected controls, respectively, whereas yields for inoculated plants with 18 or $34 \mathrm{~d}$ cold storage were $3 \%$ to $9 \%$ less than their respective controls. The main effects of nursery treatment and cold storage were highly significant for yield (Table 3), but interpretation of these results is complicated by significant year $\times$ storage and year $\times$ nursery $\times$ storage interactions. Exposure to cold temperatures in the nursery prior to harvest and in storage after harvest both affect strawberry yield (Voth and Bringhurst, 1990; Walsh et al., 1997), thus interactions between trial year and supplemental cold storage are expected regardless of nursery fumigation treatment. Post-nursery cold storage between 18 and $34 \mathrm{~d}$ are realistic commercial treatments for this cultivar at this planting location, with 21-28 d usually considered optimal for central California (Strand, 1994). Storage of 'Selva' runner plants for $6 \mathrm{~d}$ usually results in plants with relatively low vigor and thus low in productivity, whereas storage exceeding $30 \mathrm{~d}$ generates excess vegetative growth and usually reduces seasonal yield (Walsh et al., 1997). In this trial, $34 \mathrm{~d}$ of supplemental storage may have reduced yield for the con- trol plants compared with that obtainable through an optimum chilling period of $28 \mathrm{~d}$, perhaps leading to an underestimation of the detrimental consequences of $V$. dahliae infection for yield in treatment given longer cold storage.

ANOVAs for yield were conducted individually by trial year to further resolve the significant three-way interactions observed in the combined analysis (Table 4). Results from these analyses demonstrated significant cold storage effects in all trials, and significant effects of nursery treatment in two of three years. Although cold storage treatments reduced detectible levels of $V$. dahliae infection and eventual plant stunting consistently over years, translation of this disease suppression into yield advantages was less straightforward. Treatments that reduce infection rates may delay the onset of disease symptoms, providing quantitative as well as qualitative consequences for yield. Furthermore, when infection rates are moderate and the cultivar possesses some resistance, the negative consequences of excess cold storage for plant vigor and productivity may negate any positive results for disease suppression.

Although our results demonstrate substantial reduction in $V$. dahliae infection rate for the strawberry cultivar 'Selva' with cold storage treatments of $18 \mathrm{~d}$ or longer, substantive unknowns remain. Our results are not consistent with an explanation that postulates static pathogen levels and increased plant tolerance as the result of cold storage. However, the mechanism of reduced infection rate is not known, and separate experiments will be needed to determine whether cold treatment has a direct effect on $V$. dahliae, or whether cold induces secondary resistance functions that affect the pathogen. Also, although the percentage of plants with disease detectible by the petiole assessment procedure was consistent with the percentage eventually expressing visible disease symptoms, both responses may depend on disease thresholds, thus predicting the consequences of cold storage for disease expression at inoculum levels different from those tested here is not possible. Plant vigor and yield are affected by cold accumulated both in the nursery and due to treatments applied after nursery harvest. In our experiments, only responses to post-nursery cold treatments were investigated. The yearly variation for preharvest nursery chilling did not affect initial infection rates or the percentage of stunted plants (Table 3) in our trials, but larger differences over years or nursery locations are possible (Walsh et al., 1997), and may be a larger factor than indicated by these results. Regardless, the marginal benefits of reduced $V$. dahliae infection observed here were consistent over a range of cold storage treatments. If this phenomenon is common to other strawberry genotypes, $V$. dahliae may be less of a problem in cultivars adapted to cold storage.

\section{Literature Cited}

Albregts, E.E. and C.M. Howard. 1985. Short-term cold storage and soil fertility during plant and fruit production on growth and fruiting of strawberry. HortScience 20:411-413.

Davis, J.R., O.C. Huisman, D.T. Westerman, S.L. Hafez, D.O. Everson, L.H. Sorensen, and A.T. Schneider. 1996. Effects of green manures on Verticillium wilt of potato. Phytopathology 86:444-453.

Durner, E.F., J.A. Barden, D.G. Himelrick, and E.B. Poling. 1984. Photoperiod and temperature effects on flower and runner development in day-neutral, Junebearing, and everbearing strawberries. J. Amer. Soc. Hort. Sci. 109:396400.

Durner, E.F., E.B. Poling, and E.A. Albregts. 1987. Early season yield responses of selected strawberry cultivars to photoperiod and chilling in a Florida winter production system. J. Amer. Soc. Hort. Sci. 112:53-56.

Gordon, T.R., S.C. Kirkpartick, D.V. Shaw, and K.D. Larson. 2001. Differential infection of mother and runner plant generations by Verticillium dahliae in a high elevation strawberry nursery. HortScience 37:927-931.

Larson, K.D. 1994. Strawberry, p. 271-297. In: B. Schaffer and P.C. Andersen (eds.). Handbook of environmental physiology of fruit crops, Vol. I. Temperate fruits. CRC Press, Boca Raton, Fla.

Larson, K.D. and D.V. Shaw. 1995. Strawberry nursery soil fumigation and runner plant production. HortScience 30:236-237.

Larson, K.D. and D.V. Shaw. 2000. Soil fumigation and runner plant production: A synthesis of four years of strawberry nursery field trials. HortScience 35:642-646.

Paulus, A.L. 1990. Fungal diseases of strawberry. HortScience 25:885-889.

SAS Institute. 1988. SAS/STAT users guide, release 6.03 ed. SAS Inst., Cary, N.C. 
Shaw, D.V., W.D. Gubler, K.D. Larson, and J. Hansen. 1996. Genetic variation for field resistance to Verticillium dahliae evaluated using genotypes and segregating progenies of California strawberries. J. Amer. Soc. Hort. Sci. 121:625-628.

Shaw, D.V., W.D. Gubler, and J. Hansen. 1997. Field resistance of California strawberries to Verticillium dahliae 2 at three conidial inoculum concentrations. HortScience 32:711-713.

Strand, L.L. 1994. Integrated pest management for strawberries. Univ. of California, DANR publication 3351. Univ. of California Press, Oakland.

Steele R.G.D. and J.H. Torrie. 1980. Principals and procedures of statistics, second edition. McGraw-Hill, New York.

Thomas, H.E. 1932. Verticillium wilt of strawberries. Univ. Calif. Agr. Expt. Sta. Bul. 530.

Voth V. and R.S. Bringhurst. 1970. Influence of nursery harvest date, cold storage, and planting date on performance of winter planted California strawberries. J. Amer. Soc. Hort. Sci. 95:496-500.

Voth, V. and R.S. Bringhurst. 1990. Culture and physiological manipulation of California strawberries. HortScience 25:889-892.

Walsh, D.B., F.G. Zalom, N.C. Welch, and D.V. Shaw. 1997. Preplant cold storage of strawberries: Effects on plant vigor, yield, and spider mite (Acari: Tetranychidae) abundance. J. Econ Entomol. 90:818-823.

Welch, N. 1989. Strawberry production in California. Univ. of Calif., Coop. Ext. leaflet \#2959.

Wilhelm, S. and E.C. Koch. 1956. Verticillium wilt controlled. Calif. Agr. 10:3-14.

Wilhelm, S. and A.O. Paulus. 1980. How soil fumigation benefits the California strawberry industry. Plant Dis. 64:264-270.

Wilhelm, S., R.C. Storkan, and J.M. Wilhelm. 1974. Preplant soil fumigation with methyl bromide-chloropicrin mixtures for control of soil-borne diseases of strawberries-A summary of fifteen years of development. Agr. and Environ. 1:227-236. 